\title{
La poética del fragmento: estructura y escritura en Formas de Volver a Casa de Alejandro Zambra ${ }^{1}$
}

\author{
The poetics of fragmentation: structure and writing in Alejandro Zambra's Formas \\ de Volver a Casa.
}

Jaime Amaro $^{2}$

\begin{abstract}
Resumen
El presente artículo analiza la novela de Alejandro Zambra Formas de Volver a Casa a partir de su estructura y la escritura a la que esta recurre. Para ello se consideran las postulaciones de Carlos Hernández respecto de la poética del fragmento. En este sentido se da cuenta de la fragmentariedad y metaficción de la obra como estrategias que dan cuenta de la desintegración del Chile post-dictatorial y se observa la utilización de este recurso como un medio para encontrar un lenguaje apropiado para retratar adecuadamente el dolor.
\end{abstract}

Palabras clave: Alejandro Zambra, Formas de Volver a Casa, fragmento, metaficción, escritura.

\begin{abstract}
The present article analizes Alejandro Zambra's novel Ways of Going Home considering its structure and the way of writing that it draws on. In order to do so, Carlos Hernandez' nominations about the poetics of fragments are considered. In this context, it explains the fragmentariness and the metafiction of the writing as strategies that reflect the Chilean post-dictatorial disintegration and the way that this resource is used to find a suitable language to properly portray grief.
\end{abstract}

Keywords: AlejandoZambra, Ways of Going Home, fragments, metafiction, writing.

\section{Introducción}

En el presente artículo se pretende indagar sobre la poética del fragmento en la novela Formas de volver a casa de Alejandro Zambra. Esta lectura es propuesta por Carlos Hernández en su libro Poéticas del relato criminal: la violencia en la novela chilena de la dictadura (1973-1989). A pesar de que este último establece que la novela de Zambra posee estas características y, por ende, forma parte de la clasificación de la poética del fragmento en la medida que da cuenta de múltiples fracturas y, en cierto sentido, es una manifestación de la crisis en el relato, no realiza un análisis de

\footnotetext{
${ }^{1 *}$ Una primera versión de este trabajo fue presentado en el XX Congreso de la Sociedad de Escritores de Chile, SOCHEL, 2016.

${ }^{2 *}$ Docente del Colegio Carampangue, Talagante, Chile. Correo: jjmandolini@gmail.com
} 
la misma. En segundo lugar, se pretende comprender la relación dialógica que la novela establece entre el tema de la metaliteratura y la fragmentariedad.

Formas de volver a casa es un texto que cuenta la historia de un personaje anónimo que se esmera en escribir una novela basada en sus propias vivencias. El relato asume un tono autorreferencial e intimista que lleva al lector a experimentar una historia personal. Por lo mismo la trama se muestra fragmentada, intercalando relatos. El primero es asumido como una creación literaria y el segundo como la historia del autor del primer relato. En este contexto ambos textos se van relacionando y conectando, no sólo porque uno es creado dentro del otro, sino porque el autor ficticio utiliza de manera referencial su propia historia. Su estructura aparece, por ende, de manera compleja, confundiendo un relato con el otro, intentando reconstruir una memoria perdida en la historia de Chile, creando una verdad personal.

Conviene preguntarse inicialmente ¿en qué medida se desarrolla la poética del fragmento en la novela Formas de volver a casa? ¿Qué función cumple esta poética dentro del texto? ¿Es meramente una estrategia estética, o tiene otro sentido? ¿Consiste, como plantea Hernández, en buscar un lenguaje y un modo de representar el horror del período dictatorial? ¿Se limita la obra solamente a indagar en el pasado para reconstruir una memoria? ¿Existe un sentido diferente para representar la dicotomía entre realidad y ficción? En primera instancia es posible indicar que la fragmentariedad evidente del texto está ligada a la metaliteratura, pues los dos relatos tienen como nexo precisamente el carácter de ficción que asume uno y de referencialidad del otro. Cabe destacar que ambas historias presentan grandes vacíos. Se crea efectivamente un lenguaje particular y heterogéneo que va hilando la memoria personal e histórica con retazos, con experiencias privadas e íntimas, pero aparentemente existe en la dicotomía realidad-ficción planteada en la obra el interés de presentar las verdades como relativas (los hechos ocurridos de una manera pueden recordarse $o$ interpretarse de otra), de este modo si la ficción dentro de la ficción se convierte en una verdad posible, también la Historia puede, a la inversa, relativizarse, es decir, se puede poner en duda su carácter veraz. Por otro lado, la fragmentariedad no depende exclusivamente de la metaficción, sino que va adquiriendo independencia tanto en los aspectos más simples de la forma como en la configuración de algunos elementos de su contenido.

En síntesis, se propone la hipótesis de que la fragmentariedad y la metaliteratura presentes en esta obra dialogan de tal manera que crean un modo de representación que da cuenta de una historia personal "real" que se contrapone a una manera particular de contar y recordar al construir un relato "ficticio". Creando en la ficción, entendida como una realidad independiente dentro de su propia dimensión, una verdad que logra aflorar más allá de la verosimilitud, poniendo en crisis el relato asumido en su forma, mostrando una historia destrozada, fragmentada que tiene el sentido de retratar el dolor y las dudas tras la dictadura. Esta fragmentación se instala de una manera distinta respecto de las novelas de Eltit (Lumpérica y Por la Patria), posiblemente porque la distancia temporal que la novela de Zambra posee respecto de los acontecimientos reales es mucho mayor en relación a la obra de Eltit. Esta fragmentación se manifiesta en Zambra por medio de la creación de una realidad nueva que se sirve tanto de lo referencial como de lo imaginado, por su parte Eltit desintegra la unidad y continuidad narrativa del relato. Evidentemente la fragmentación en ambos autores se expresa de un modo muy diferente, pero ambas estrategias logran el efecto de plasmar el dolor y los cuestionamientos postdictatoriales. Para rastrear acerca de los temas propuestos y demostrar la hipótesis se indagará en primera instancia sobre los diferentes aspectos que puedan mostrarse como fragmentados dentro de la novela a nivel estructural, a saber, la configuración de 
capítulos, el uso del lenguaje, la cronología y la metaficción para luego reflexionar respecto del sentido que adquiere la poética del fragmento dentro de esta novela.

Resulta imprescindible definir dos conceptos clave propuestos en la hipótesis de este trabajo: la poética del fragmento y la metaficción.

La clasificación propuesta por Carlos Hernández depende principalmente de los modos de representación y de los lenguajes empleados en las mismas, es decir, desarrolla su pensamiento teórico a partir de la estética que proponen las obras literarias para resolver el complejo problema de encontrar un lenguaje apropiado para expresar el horror y un modo que sea capaz de representar un período histórico muy difícil de manifestar, incluso, por medio de la ficción. Hernández plantea, de este modo, la poética del relato criminal, la que considera que la violencia de la dictadura produce una reformulación en la escritura en términos del lenguaje y la representación. A partir de esta poética Hernández propone que en el período mencionado se construyen proyectos escriturales muy heterogéneos relacionados con el proceso de enunciación. Estos proyectos se insertan dentro de variados ejes, de los cuales destacamos el de la poética del fragmento, ésta es definida por Hernández como una:

(...) modalidad discursiva compleja que da cuenta de las múltiples fracturas (sociales, culturales, históricas, físicas) a las que fue sometido el país durante la dictadura. En estas obras se evidencia una crisis del relato o de una linealidad en términos argumentales, asumiendo el protagonismo de éstas la fractura discursiva. (2014, p.37)

Hernández (2014), estudia dos novelas de Diamela Eltit (Lumpérica y Por la Patria). Respecto a estas obras el autor explica que funcionan como collage, pues la linealidad tradicional desaparece, lo que permite observar las fracturas de la sociedad de un país en dictadura. Hernández concluye diciendo que en estas obras en específico el acontecer de la novela pierde relevancia, pues lo importante es la imagen fragmentada del texto que refleja a la sociedad fracturada por el poder dictatorial. Es claro que la manifestación de la poética del fragmento en las novelas de Eltit es distinta en relación a la obra de Zambra. En este sentido es importante aclarar que estas obras surgen en momentos diferentes y utilizan medios distintos para lograr un mismo objetivo: encontrar un lenguaje nuevo que permita dar cuenta del sufrimiento postdictatorial, es por ello que los análisis de Hernández resultan de utilidad para este estudio, pues entregan ciertas bases teóricas esenciales, especialmente aquellas que tienen que ver con la búsqueda de un lenguaje apropiado para dar cuenta de los acontecimientos traumáticos de la dictadura y postdictadura.

Además de la noción de fragmentariedad propuesta por Hernández, conviene establecer una definición de metaliteratura. Cabe destacar que este tema ha sido estudiado en múltiples oportunidades, por ello se considerará para construir una definición que nos aproxime a encontrar una respuesta a este tema las postulaciones de Antonio Jesús Gil (2001) y Laura Vizcaíno (2013) sobre el concepto de metaficción y a Lucien Dällenbach (1991) respecto de la definición de mise en abyme. El primero plantea que:

En líneas generales, se caracteriza la metaficción como la exhibición de la condición de artificio de la obra literaria (...). Esta dimensión de la novela metaficcional de atraer la atención sobre su composición y artificiosidad ha sido desde entonces la base conceptual del fenómeno. (p.44) 
Del mismo modo, Laura Vizcaíno (2013) propone que "la metaficción es un acto de autorreflexión que ocurre dentro del mismo texto (sobre el lenguaje, la escritura, la literatura), y en este sentido es una especie de autocrítica" (p.87). Dällenbach define, por su parte, que mise en abyme corresponde a "todo enclave que guarde relación de similitud con la obra que lo contiene" (1991, p.61). Sintetizando estas tres definiciones es posible postular que la metaficción es un artificio que hace evidente su artificiosidad, creando al mismo tiempo una autorreflexión del texto y realizando una repetición estética del texto dentro de sí mismo. Es importante destacar que, a partir de las definiciones entregadas, puede entenderse que la metaficción es una estrategia estética, pero también es un modo de autorreflexión y autocrítica. Es por esto que el uso de esta estrategia no resulta gratuito, sino que tiene un sentido mucho más profundo.

\section{La estructura y la escritura.}

Formas de volver a casa es una novela que presenta la fragmentariedad en variados niveles. A pesar de ello no parece ser una obra semejante a las que Hernández analiza. En el caso de Lumpérica, por ejemplo, nos encontramos frente a una obra que se caracteriza porque su trama se ve perdida en su desarrollo, no parece importar tanto qué pasa, sino que destacan los recursos que llevan, precisamente, a que la historia se vuelva cada vez más difusa. En ese sentido la novela de Zambra no presenta ese nivel de fragmentariedad, pues aunque se aplique esta poética puede encontrarse y describirse una trama. Estas diferencias pueden entenderse porque la obra de Zambra se ha desarrollado en un contexto en el que la narrativa chilena ha cambiado, es por ello que su novela construye un lenguaje distinto en comparación a las novelas de Eltit.

La poética del fragmento puede aplicarse de dos maneras, en primer lugar observando elementos estructurales junto con aspectos escriturales y, en segundo lugar, dando cuenta de la configuración de los personajes. Acá se intentará indagar acerca de lo primero. Se pretende subdividir esta lectura en tres partes: una que se dedique a la estructura de la novela en general y sus capítulos, observando la manera en la que actúa la cronología y la metaficción; otro que se centre en la reiteración en el uso del lenguaje, y un último subapartado que se dedique al tema de los géneros que se desarrollan a lo largo de la obra.

\section{a. Estructura de la novela, su cronología y la metaficción.}

Esta obra se estructura en cuatro capítulos que dan cuenta de dos dimensiones diferentes, los capítulos I y III (Personajes secundarios y Literatura de los hijos, respectivamente) cuentan una historia entendida dentro de la misma novela como ficticia y que relata la manera en la que el protagonista, personaje sin un nombre conocido, pero que es apodado como "Aladino", se relaciona con su experiencia en torno al Golpe Militar. Esta historia se enmarca dentro de las vivencias del escritor de este relato presentadas en los capítulos II y IV (Literatura de los padres y Estamos bien), los que funcionan como el diario del autor, el que tampoco tiene nombre, aunque presenta múltiples rasgos que lo asemejan bastante al autor real de la novela. En esta segunda historia el narrador reflexiona en torno a la escritura, a la memoria y a la política.

Los capítulos se subdividen en pequeñas narraciones, en el caso de la "novela" encontramos escrituras de dos o tres páginas que cuentan un acontecimiento o anécdota no siempre relacionada con la siguiente. Muchas veces el criterio para realizar esta división es un salto temporal, aunque 
este criterio no es absoluto. A modo de ejemplo puede mencionarse en el primer capítulo la escena en la que el protagonista se pierde de sus padres. Tras realizar esta narración, el tiempo se mueve dos o tres años en el siguiente fragmento, cuando ocurre el terremoto de 1985 (Zambra, 2011). Este tipo de construcciones narrativas van configurando una historia que se va ajando, dejando a su paso muchos espacios en blanco. De este modo la manera de entender el tiempo contribuye a la configuración de la poética del fragmento en el sentido que no existe un orden para construir la cronología.

Por otro lado, el "diario" se subdivide de una manera diferente, en este caso encontramos fragmentos de variadas extensiones (desde algunas páginas hasta pequeños párrafos) que se separan por medio del uso de un asterisco $(*)$. En este caso la fragmentariedad parece romper de manera mucho más marcada la cronología del relato. El autor cuenta un hecho, de pronto recuerda otro y en la gran mayoría de los casos no establece una relación entre uno y otro fragmento, tampoco suele entregar marcas textuales claras acerca del momento que está narrando. Puede mencionarse como ejemplo el episodio en el que recuerda un momento de la adolescencia. Aquí explica que su profesor entra en pánico tras escuchar unos balazos lejanos, pues cree que la dictadura ha regresado y luego, sin ningún aviso, relata una anécdota de un viaje a Punta Arenas en el que una mujer le pregunta su seudónimo.

Puede sintetizarse por lo expuesto anteriormente que la manera en la que se trata el tiempo a lo largo de la obra muestra una clara tendencia a la fragmentariedad en el sentido que rompe con la concepción lineal clásica de la cronología, pero sobre todo porque muestra una tendencia a dejar espacios vacíos.

Es importante mencionar que estos relatos ("novela" y "diario"), a pesar de presentarse y entenderse de manera independiente, dentro de la novela poseen un punto de conexión: el uso de la metaficción. Dicho de otro modo, no sólo están unidos porque uno es concebido dentro del otro, sino que el relato "ficticio" se nutre de las experiencias del autor del plano "real" de la novela.

La metaficción se vuelve evidente a partir del segundo capítulo, pues el narrador enuncia la actividad escritural y la existencia del manuscrito que su ex pareja no quiere leer. De este modo surgen escenas en las cuales el narrador reflexiona en torno a la relación entre la escritura y la memoria:

Escribo en casa de mis padres. Hace tiempo que no venía. Prefiero verlos en el centro a la hora del almuerzo. Pero esta vez quise seguir con mi papá el partido entre Chile y Paraguay, pensando también en refrescar algunos detalles del relato. Es el viaje de la novela, el viaje de vuelta que hace el protagonista, asustado, al final de esa tarde larga en la que sigue a la supuesta novia de Raúl. Escribí ese pasaje pensando en un viaje real, más o menos a esa edad. (Zambra, 2011, p.74)

En este fragmento el autor confiesa que la escena en la que sigue a una mujer que es, bajo sus deducciones, la novia de Raúl y que ocurre en el primer capítulo, corresponde a un recuerdo personal, es decir, la escena ficticia corresponde a una reinterpretación de una vivencia. De este modo se hace un nexo entre ambas narraciones que va mucho más allá de aplicar un juego estético. En este caso se hace un rescate de la memoria, dándole un sentido nuevo. Algo similar ocurre algunas páginas más adelante, cuando el narrador pasa cerca de la casa que él concibió como la de 
su personaje Claudia: "Quería ver la casa de Claudia, que en realidad fue, durante mucho tiempo, la casa de mi amiga Carla Andreu” (Zambra, 2011, p.76).

Otra escena muestra a la hermana del narrador preguntándole sobre la novela que está escribiendo:

¿Salgo yo en tu libro?, dice al fin.

No.

¿Por qué?

Lo he pensado. Claro que lo he pensado. Lo he pensado mucho. Mi respuesta es honesta:

Para protegerte, le digo. (...).

¿Y tú sales en el libro?

Sí. Más o menos (...).

¿Y salen nuestros padres?

Sí. Hay personajes parecidos a nuestros padres. (Zambra, 2011, p.82)

En este caso puede observarse que el autor realiza una selección de la información referencial que utiliza en la escritura de su libro. Al construir a los personajes piensa en sí mismo y en sus padres, pero también decide no incluir a su hermana a pesar de que ella sí participa de la historia. Este proceso de selección muestra que el autor posee la intención de contar cierta historia y no necesariamente ser fiel a los acontecimientos tal cual ocurrieron, de este modo se selecciona la memoria, construyendo algo diferente que reinterpreta los acontecimientos. Dicho de otro modo, la selección de información corresponde a la aplicación de la metaficción que va fragmentando la narración con el objetivo de reorientar la experiencia vivida por medio de la ficción.

Este proceso de selección de información queda en evidencia en una escena de la novela que es escrita de dos maneras. La primera ocurre en el plano "real" cuando se narra la visita del protagonista a la casa de sus padres para ver un partido de fútbol, y luego una conversación con la madre mientras fuman durante la madrugada (Zambra, 2011). Esta escena es reescrita más adelante en el relato "ficticio", en este caso el protagonista no va solo, sino acompañado de Claudia y el motivo del encuentro es, en este caso, simplemente una visita. En la narración de esta escena se agrega una discusión con el padre sobre la calidad ética de las personas que roban y de política; también se incluye una conversación con la madre mientras fuman en la madrugada, y se relata un encuentro sexual entre Claudia y el protagonista (Zambra, 2011). La reescritura de esta escena muestra, al igual que la selección de los personajes que aparecerán o no en la obra, la intención de darle un rumbo determinado al relato, reinterpretar la memoria otorgándole un objetivo concreto. Barraza y Plancarte (2016) dan cuenta de la reescritura de esta escena, ellas explican que en la representación "real" el narrador pone hincapié en detalles banales, como los gestos de la madre al fumar y, del mismo modo, la trivialidad de la conversación. Por su parte, en la reescritura "ficticia", se aborda “(...) el gran tema de la postdictadura chilena: el de la culpa y la inocencia” (p.37). Más adelante las mismas autoras reflexionan en torno al tema, llegando a la conclusión de que la reescritura tiene como trasfondo un:

“(...) problema generacional: la dificultad de manejar el vacío en el que consiste la herencia de los padres. De ahí la melancolía que impregna las historias de Zambra: dan cuenta de una pérdida, de un vacío, sin que se 
sepa muy bien qué se ha perdido, qué es lo que no se puede representar. Es más, en las partes autobiográficas de las novelas de Zambra se nota incluso una cierta tristeza por la carencia de duelo, una nostalgia, precisamente, por un hogar fracturado que representara quizás mejor los años de la dictadura. La casa paterna de Zambra no es lo 'irrepresentable' (...).La banalidad de la casa 'autobiográfica' de Zambra requiere entonces los capítulos de ficción (la historia de su amiga Claudia) para seguir teniendo algo que decir. (Barraza y Plancarte, 2016, p.39)

En síntesis, es posible decir que se utiliza la metaficción como un modo de reescribir la historia, pero haciendo valer el dolor y reflexionando en torno a temas que en la dimensión "real" no son abordados de manera tan profunda y directa. Este es, en definitiva, el rumbo que el autor desea entregarle a su relato ficticio: reescribir una historia banal que valorice el dolor de una época. Dadas las características de este relato que se escribe y reescribe, se presenta una construcción que tiende constantemente a la fragmentariedad, en la medida en que selecciona información y reflexiona en torno a sí misma. También se pone en evidencia la fragmentariedad interior del autor, pues posee una historia carente de dolor, es por ello que intenta completarla por medio de la ficción. En resumen, es posible aseverar que la fragmentariedad de la forma da cuenta, al igual que la metaficción, del dolor que el protagonista no posee, pues su narración se va rompiendo en la búsqueda de él. Dicho de otro modo, al no poseer este dolor el narrador fragmenta su relato para poder representarlo.

b. La reiteración del lenguaje y la reflexión en torno a la escritura

La autorreflexión que se mencionó anteriormente se ve reflejada, por otro lado, en la escritura misma de la novela. Esto se observa, en primera medida, en una marcada tendencia a la redundancia. Por otro lado, también se advierte en las reflexiones que se realizan en torno a la creación literaria, y en la ya mencionada reescritura de escenas.

Respecto de la redundancia en la escritura puede mencionarse la escena cuando "Aladino" y Claudia dialogan respecto de las calles en las que viven: "Vivo en la villa de los nombres reales, dijo Claudia esa tarde del reencuentro, mirándome a los ojos seriamente. Vivo en la villa de los nombres reales, dijo de nuevo, como si necesitara recomenzar la frase para continuarla (...)" (Zambra, 2011, p.29). En este fragmento, además de mostrar la repetición de la misma frase, el narrador realiza un alcance explicativo al respecto, haciendo una reflexión acerca de la importancia de la reiteración para poder continuar con el relato. Más adelante ocurre algo similar cuando el narrador cuenta una anécdota en la que corrige a una profesora respecto de una falta de ortografía:

(...) no era una mala persona, pero me odiaba. Me odiaba debido a la palabra aguja, que para ella no existía. Para ella la palabra correcta era ahuja. No sé muy bien por qué un día me acerqué con el diccionario y le demostré que estaba equivocada. Me miró con pánico, tragó saliva y asintió, pero a partir de entonces dejó de quererme y yo también a ella. No deberíamos odiar a la persona que nos enseñó, bien o mal, a leer. Pero 
yo la odiaba o más bien odiaba el hecho de que ella me odiara. (Zambra, 2011, p.39)

Este fragmento resulta interesante no solo porque ejemplifica, como el anterior, la redundancia, sino también porque el autor aprovecha de comentar respecto de la escritura, de los modos correctos de escribir y que estos pueden generar odio en otros. Llevado al contexto de la novela puede interpretarse la actitud de la profesora como la imposición de cierta manera de escritura frente a otras, es decir, funcionaría como una metáfora de la Historia versus la memoria individual.

En una primera lectura puede considerarse la redundancia como una forma de lograr un efecto que genere la pérdida del sentido del lenguaje, es decir, no importa qué tanto se repita una idea, esta no cobra sentido o, por otro lado, mientras más se repite una idea más se gasta y adquiere menos valor. Esta interpretación es posible en algunos de los momentos del relato, pero si se realiza una reflexión más profunda puede encontrarse un sentido diferente a la redundancia, por ejemplo en el chiste que inventa el autor:

Cuando grande voy a ser un personaje secundario, le dice un niño a su padre.

Por qué.

Por qué qué.

Por qué quieres ser un personaje secundario.

Porque la novela es tuya. (Zambra, 2011, p.74)

En este fragmento se aprecia la repetición de la pregunta "por qué" por parte del hijo, esto puede funcionar, llevando el chiste a las diferentes situaciones expuestas en la obra, al protagonista cuestionando a su padre, como efectivamente lo hace a lo largo de la novela, respecto de, por ejemplo, su pasividad frente a la dictadura. También puede entenderse esta reiteración como un balbuceo que impide al personaje, como representante de su generación, lograr contar una historia y llegar a formar parte de la misma. Es por ello que termina siendo sólo un personaje secundario. Otra cita que permite ampliar la reflexión respecto de la repetición en el uso del lenguaje es la siguiente anotación del autor en su diario "Los padres abandonan a los hijos. Los hijos abandonan a los padres. Los padres protegen o desprotegen pero siempre desprotegen. Los hijos se quedan o se van pero siempre se van" (Zambra, 2011, p.73). En estos casos la repetición no parece restarle sentido a la idea presentada, sino que se refuerza, ampliando su valor, mostrando las diferentes aristas de una misma idea, construyendo, en definitiva, un nuevo sentido. Del mismo modo generan un efecto de fragmentariedad en la medida que muestra el intento de repetir con la intención de ampliar, pero al hacerlo el relato debe regresar sobre la misma idea, creando la sensación de que en vez de avanzar, la historia se vuelve a contar.

Otro aspecto interesante que sirve como clave para concebir la escritura como fragmentada -además de la reiteración- son las reflexiones que se hacen en la obra respecto de la escritura o de la construcción de textos. En primer lugar, encontramos tres ejemplos que metaforizan la fragmentariedad textual, uno es el muro del colegio que se derrumba tras el terremoto: "el muro que rayaban los alumnos de la media. Pensaba en todos esos mensajes volando en pedazos" (Zambra, 2011, p.20). Otro corresponde a los magnetos que Eme le regala al autor con palabras en inglés (Zambra, 2011, p.61). Estas dos imágenes pueden ser representaciones de la escritura en dos 
niveles. El muro como elemento concreto que sirve para hacer testimonio de la Historia destruida violentamente y desparramada en forma de escombro, y las frases artificiales que pueden moldearse y reordenarse a conveniencia del autor reflejarían la escritura de la Historia y la ficción. Ambas escrituras se muestran de manera fragmentada, aunque de formas diferentes, pues el muro no puede ser reconstruido tal como estaba y los magnetos, por su parte, pueden moldearse, transformándose en infinitas posibilidades de escritura.

La tercera metáfora, que apunta hacia el mismo sentido, es la que ocurre cuando "Aladino" borra accidentalmente una parte de la cinta del cassette de Raphael:

(...) Después de pensarlo un poco, creí que la única solución era cantar encima del coro, y me puse a practicar la frase impostando la voz de forma que me pareció convincente. Finalmente me decidí a grabar y escuché la cinta varias veces, creyendo, con indulgencia, que el resultado era adecuado, aunque me preocupaba la falta de música en esos segundos. (Zambra, 2011, p.25)

En este caso se observa la reconstrucción de un texto adulterado, aquí el personaje intenta reparar la cinta por medio de una treta que aparentemente funciona, pero que a él, que sabe la verdad, le genera un sentimiento de culpa. En este caso la metáfora se refiere a la obra misma, pues muestra una historia (memoria) borrada y el intento de reconstruirla, muy a pesar de que sea imposible para él dejarla tal como estaba en un principio. Dicho de otro modo, la reconstrucción de la cinta hace referencia a la reconstrucción de la memoria pues, del mismo modo que el protagonista intenta reparar el cassette, llena los espacios vacíos de la memoria con su propia voz. Podemos decir, por ende, que este relato utiliza esta metáfora haciendo referencia a la condición reconstruida de la escritura, es decir, que intenta recuperar una memoria desintegrada, rellenándola con elementos salidos de la imaginación. Se hace un juego entre realidad-ficción, historiaimaginación, memoria-invención.

Esta constitución híbrida de la novela (usa tanto la imaginación como la historia) queda clara de manera explícita tras las propias palabras del autor:

Me siento demasiado cerca de lo que cuento. He abusado de algunos recuerdos, he saqueado la memoria, y también, en cierto modo, he inventado demasiado. Estoy de nuevo en blanco, como una caricatura del escritor que mira la pantalla con impotencia. (Zambra, 2011, p.64)

Este ejemplo manifiesta de manera bastante clara la fragmentariedad del texto, entendido como un relato que crea en base a la imaginación y la referencialidad. Esto podría interpretarse como la memoria presentada con espacios vacíos y el autor intentando completarlos, pero en el fondo estos espacios en blanco trascienden al texto. Esta idea se desprende del siguiente fragmento: "(...) un libro es siempre el reverso de otro libro inmenso y raro. Un libro ilegible y genuino que traducimos, que traicionamos por el hábito de una prosa pasable" (Zambra, 2011, p.151). En este caso se entiende que tras la novela escrita existe otra historia que el narrador ha filtrado, seleccionando solo aquello que funciona para este relato. Esta idea es reforzada más adelante cuando el autor manifiesta: "Borro. Borro muchísimo. Veinte, treinta páginas. Me olvido de este libro" (Zambra, 2011, p.161). 
En síntesis, puede decirse que la repetición y autorreflexión en la escritura son evidencias claras de la fragmentariedad del texto. La presencia de esta poética no resulta sólo un recurso estético; su sentido es adquirido cuando la redundancia entrega una reinterpretación de la palabra enunciada. Es cierto que el texto da la impresión de ir desintegrándose en su reiteración, pero finalmente termina construyendo una realidad que reflexiona en torno a los modos de recordar y construir verdades. Por otro lado, las referencias y metáforas utilizadas para reflexionar en torno a la escritura muestran que el texto está fragmentado en la medida que se vale de referencias diferentes, incluso opuestas, como la historia y la ficción; la memoria y la imaginación o la realidad y la invención. Del mismo modo muestran la incapacidad del narrador de plasmar la memoria tal cual él la percibe, en contraposición a la necesidad urgente de representarla.

\section{c. El tema del género}

A lo largo de esta obra el narrador utiliza al menos cuatro géneros diferentes en la búsqueda de un lenguaje que lo ayude a representar el tema en cuestión. El primero y segundo son los más evidentes y corresponden a la novela y al diario; el tercero es la crónica, y el último es el género lírico. No se dará cuenta de los dos primeros porque ya se ha ahondado en ellos en los apartados anteriores.

A pesar de que este relato corresponde a una ficción, usa en un momento el género de la crónica cuando replica prácticamente de manera íntegra el texto "Lecturas obligatorias" del libro No Leer del mismo autor. Ambos textos varían sólo al final, pues en la novela se trata el tema escolar del ensayo para comenzar a narrar otra escena (Zambra, 2011).

La presencia de esta crónica muestra la intención de confundir al lector respecto del género al cual se enfrenta, pues por su propia naturaleza la crónica corresponde a un texto no ficcional, pero dentro de la novela este valor se subvierte. De este modo es posible cuestionar la naturaleza ficcional del texto en sí al imaginar que otras escenas podrían estar basadas, como esta, en la realidad del autor real.

Se inserta además, como ya se dijo, otro género literario: la poesía. Estos textos poéticos surgen sólo en dos ocasiones, a pesar de su brevedad, terminan siendo claves importantes de la obra. Cabe mencionar que antes de presentar los poemas el narrador evidencia problemas en la escritura:

La prosa me sale rara. No encuentro el humor, la tesitura. Pero suelto algunos endecasílabos y de pronto me dejo invadir por ese ritmo. Muevo los versos, confirmo y transgredo la cadencia, paso horas trabajando en el poema. Leo en voz alta:

Es mejor no salir en ningún libro Que las frases no quieran abrigarnos Una vida sin música ni letra

Y un cielo sin las nubes que hay ahora

No sabes si regresan o se van Las nubes cuando cambian tantas veces

De forma y pareciera que seguimos

Habitando el lugar que abandonamos

Cuando no conocíamos los nombres 
De los árboles

Cuando no conocíamos los nombres

De los pájaros

Cuando el miedo era miedo y no existía

El amor al miedo

Ni el miedo al miedo

Y el dolor era un libro interminable

Que alguna vez hojeamos por si acaso

Salían nuestros nombres al final. (Zambra, 2011, p.153)

Se advierte en primera instancia la dificultad del autor para encontrar la manera adecuada de continuar con su relato. Esto cambia cuando utiliza el género lírico, de ese modo el narrador consigue construir los versos que le permiten expresar aquello que por medio de la prosa no le es posible. Cabe destacar que el poema pareciera enunciar un aspecto contrario al que se plantea en la novela, pues explica la preferencia al ocultamiento y no al desenmascaramiento, es decir, que el autor se anula como personaje. El poema también hace referencia al paso del tiempo, pues las nubes se muestran en un constante cambio, pero el hablante parece sentir que no avanzan, que permanecen en el mismo lugar. Finalmente se hace referencia al miedo y al dolor. En este caso puede interpretarse que el hablante no vive de primera mano estos sentimientos, es por ello que termina buscándolos en la ficción.

Un segundo poema aparece algunas páginas más adelante, en este caso se introduce, al igual que el anterior, un enunciado que muestra la dificultad del autor ante el proceso de escritura narrativa y tener que recurrir al verso como solución:

Y luego, al despertar, escribo versos y descubro que eso era todo: recordar las imágenes en plenitud, sin composiciones de lugar, sin mayores escenarios. Conseguir una música genuina. Nada de novelas, nada de excusas.

Ensayo borrarlo todo y dejar que prevalezca solamente ese ritmo, esas palabras:

La mesa consumida por el fuego

Las marcas en el cuerpo de mi padre

La rápida confianza en los escombros

Las frases en el muro de la infancia

El ruido de mis dedos vacilando

Tu ropa en los cajones de otra casa

El ruido interminable de los autos

La cálida esperanza de volver

Sin pasos sin camino de memoria

La larga convicción de que esperamos

Que nadie reconozca en nuestra cara

La cara que perdimos hace tiempo. (Zambra, 2011, p.161-162) 
Este poema resulta interesante porque utiliza variadas imágenes que han aparecido a lo largo de la novela, por ejemplo la mesa en el fuego, el muro del colegio derrumbado o la marca que deja el accidente del padre. También se hace referencia al proceso de escritura en el quinto verso y a Eme cuando menciona la ropa en los cajones de otra casa. Por último la esencia misma de la novela aparece en el verso que hace mención al retorno (regreso al hogar) y a la metamorfosis final del hablante, en la que pierde su rostro, su identidad a lo largo del tiempo. Este poema podría sintetizar a la novela misma, pero usando como recurso el género lírico. Somos testigos una vez más del proceso de selección de los recuerdos, pues el poema no da cuenta de la obra de manera íntegra, sino de algunas imágenes significativas de ella, por ende surge la fragmentariedad en la composición de este poema.

La incorporación de la poesía dentro de esta novela surge como un recurso del narrador para representar aquello que la narrativa no permite, es decir, surge como un mecanismo para intentar plasmar una realidad marcada por el horror y que, por ende, se vuelve irrepresentable. Al respecto explica Rancière que:

[Hay un uso] inflacionista de la noción de irrepresentable y de toda una serie de nociones a las cuales ésta se conecta fácilmente: lo impresentable, lo impensable, lo intratable, lo irredimible, etcétera. En efecto, este uso inflacionista hace caer bajo el mismo concepto y rodea de un mismo aura de terror sagrado toda clase de fenómenos, de procesos y de nociones que van desde el interdicto mosaico de la representación hasta la Shoah, pasando por lo sublime kantiano, la primitiva escena freudiana, el Grand Verre de Duchamp o el Carréblanc sur fondblanc de Malevith. (cit. en Didi-Huberman, 2004, p.229)

En este sentido es posible decir que, en el caso de la novela de Zambra, un recurso "inflacionista" corresponde al uso de la poesía, pues logra expresar una realidad revestida de un aura de terror sagrado. De este modo el narrador consigue enunciar aquello que es imposible de representar por medio de otras formas de lenguaje.

En síntesis puede plantearse que la utilización del narrador de diferentes géneros surge, en el caso de la crónica, para cuestionar la referencialidad de la novela, pues la presencia de ella y su relación con la no ficción desencajan con el contexto "ficcional" de la obra, es decir, su presencia permite cuestionar esta escena ya que se ha presentado en No Leer como un relato no ficticio. Si puede hacerse este planteamiento puede cuestionarse, a su vez, la referencialidad del resto de la novela, es decir, si una escena pertenece a un género de la no ficción, otras pueden pertenecer, del mismo modo, a vivencias personales del autor. En el caso de la lírica, todo parece indicar que su presencia se relaciona con encontrar un lenguaje que resulte más apropiado para hacer referencia al dolor y al miedo vivido por el narrador ante el tema al que se ve enfrentado: la dictadura, es decir, aparece porque el lenguaje del género narrativo se muestra más limitado respecto de su capacidad de expresar el intenso dolor que produce el tema y, del mismo modo, la dictadura resulta un asunto tan delicado y complejo de tratar que es necesario buscar mecanismos que sean más pertinentes para expresarlo. Es decir, es el resultado de la búsqueda de un lenguaje que narre lo irrepresentable. De este modo se aplican a la novela las postulaciones de Carlos Hernández: en la obra se manifiesta la poética del fragmento en la medida que busca un nuevo lenguaje representacional. 


\section{Conclusión}

El presente trabajo planteó los objetivos de indagar la fragmentariedad de la novela Formas de volver a casa y de comprender la relación que esta técnica plantea con la metaliteratura. En este sentido puede decirse que el fragmento se desarrolla en variados aspectos de la novela, por ejemplo en su estructura y en la escritura misma, pero estos elementos no agotan la poética del fragmento en la novela. Pueden mencionarse aspectos del contenido de la obra como la configuración de la identidad de los personajes que, por existir en dos planos de la ficción, se vuelve tremendamente ambigua. Respecto de la relación dialógica entre el fragmento y la metaficción, basta decir que la segunda estrategia funciona como un punto de conexión entre la "novela" y el "diario".

Por otro lado, se propuso la hipótesis de que el diálogo entre la fragmentariedad y la metaficción crean un modo de representación que considera una historia "real" y una "ficticia", creando en la ficción una verdad que trasciende la verosimilitud y que pone en crisis el relato con el fin de retratar el dolor y las dudas postdictatoriales, generando una realidad nueva.

Para demostrar esta hipótesis se analizó la novela a nivel estructural, considerando cada capítulo como un fragmento de una gran historia y, a su vez, la estructura interna de cada uno de ellos como un conglomerado de pequeños fragmentos que rompen la concepción tradicional de tiempo y que deja a su paso espacios en blanco. Por su parte, la metaficción surge con el fin de reinterpretar la memoria, volviendo a contar de modo ficticio algunas escenas de tal manera que se reorienta la historia, creando una fragmentación que le otorga un sentido nuevo al relato que valida el dolor al contar un hecho que no es real, pero que incluye elementos reales, como el dolor. Visto desde otra perspectiva, el dolor se representa aquí por medio del fragmento, pues al buscarlo la historia se rompe ya que la memoria del narrador está libre de este sentimiento y debe recurrir a la imaginación para completar su memoria. De este modo el dolor se logra retratar por medio de una narración imaginada.

También se indagó respecto de la redundancia en el uso del lenguaje como una forma de ampliar el sentido, mostrando diferentes dimensiones de la misma idea y creando un rumbo nuevo. En este caso la fragmentariedad surge porque el relato se ve obligado a volver sobre sí mismo, dando la impresión de que en vez de avanzar se detiene constantemente en torno a las mismas ideas. Por otro lado se analizaron diferentes metáforas y reflexiones que tienen relación con la escritura y que dan cuenta de ella como algo que aparece en el relato de manera fragmentada, evidenciando la dicotomía entre la realidad y la ficción y, del mismo modo, mostrando la incapacidad de plasmar la memoria tal cual es en contraste a la necesidad de representarla.

Finalmente se consideró para esta lectura la presencia de varios géneros en la obra, destacando la crónica y la poesía. La primera parece surgir con la intención de cuestionar la referencialidad del texto y la segunda como una manera de encontrar un lenguaje más propicio para representar a la Dictadura debido a su complejidad y al dolor que se relacionan con ella.

Cabe destacar que todos los elementos estudiados a lo largo del presente artículo dan cuenta de una representación fragmentada del relato. Esta poética no surge, como ya se ha planteado, de forma meramente estética, sino que aparece con el fin de representar apropiadamente una realidad oscura en la Historia de Chile, un acontecimiento caracterizado por la dicotomía entre el testimonio 
de quienes lo vivieron y la verdad impuesta por la Historia. En este contexto la obra resulta un gran aporte en la medida que representa de manera eficiente los cuestionamientos de los llamados hijos de la dictadura, del mismo modo la fragmentariedad representada muestra las fracturas sociales, políticas, emocionales e históricas que dejó como consecuencia la dictadura militar, es decir, las fisuras que caracterizan a todo un país a partir del Golpe Militar se ven reflejadas desde la estructura de esta obra. En este sentido, la novela de Zambra da cuenta de una historia políticosocial que se encuentra en disputa, marcada por los silencios, por la multiplicidad de versiones e incoherencias. Este hecho ha dado cabida, tal como lo refleja la obra, al empleo de la imaginación como un recurso para completar la historia de Chile. Cabe destacar que la poética fragmentada no resulta una estrategia exclusiva de los relatos dictatoriales o post dictatoriales, pero en este caso el recurso sirve como un medio para representar lo irrepresentable. Del mismo modo es pertinente aclarar que las manifestaciones de esta poética son variadas, por ejemplo, en las obras de Eltit la trama va perdiendo relevancia y destaca la estructura ruinosa de la novela como reflejo de la desintegración social; en el caso de Zambra, la trama no desaparece, sino que es reinterpretada por medio de la imaginación y la metaficción. A pesar de que las manifestaciones resultan diferentes, el objetivo es bastante similar: dar cuenta por medio de un lenguaje nuevo del sufrimiento humano y de las fisuras sociopolíticas que la dictadura trae como consecuencia.

En síntesis, es posible concluir que esta novela utiliza la poética del fragmento como una estrategia que permite dar cuenta del dolor y de los cuestionamientos propios de quienes heredaron los problemas instalados por la dictadura. Del mismo modo, esta estrategia aparece como un medio para encontrar un lenguaje que resulte pertinente para tratar este tema por la gran dificultad y delicadeza representacional que implica. Finalmente puede decirse que la estrategia dialógica entre la metaficción y la poética del fragmento ponen en crisis la veracidad autoimpuesta de la Historia en la medida que la obra permite crear un relato nuevo que involucra elementos imaginarios. $\mathrm{Si}$ esta obra fragmentada puede realizar este movimiento, también cabe la posibilidad que la Historia, metaforizada en un muro destruido, lo haga. De este modo la novela Formas de volver a casa logra reconstruir la memoria, pero al mismo tiempo va mucho más allá, termina creando una realidad nueva que, a pesar de ello, logra retratar el sufrimiento y el trauma de la post dictadura chilena.

\section{Bibliografía}

Barraza, L., \& Plancarte, M. (2016). Memoria y naufragio en Formas de volver a casa de Alejandro Zambra. Perífrasis 7.13, pp. 99-112.

Dällenbach, L. (1991). El relato especular. Madrid: Visor.

Didi-Huberman, G. (2004). Imágenes pese a todo. Memoria visual del Holocausto. Barcelona: Paidós.

Gil González, A. (2001). Teoría y crítica de la metaficción en la novela española contemporánea. Salamanca, España: Ediciones Universidad de Salamanca.

Hernández Tello, C. (2014). Poéticas del relato criminal: violencia en la novela chilena de la dictadura (1973-1989). Santiago de Chile: Oxímoron.

Viú, A. (2007). Imaginar el pasado, decir el presente. Santiago, Chile: RIL Editores.

Vizcaíno, L. (2013). La metaficción en algunas brevedades narrativas de Hispanoamérica. Cuadernos Americanos. 143. Pp. 87-101.

Zambra, A. (2016). No leer. Santiago de Chile: Universidad Diego Portales.

Zambra, A. (2011). Formas de volver a casa. Barcelona: Anagrama. 